\title{
Christian GROSSE, Les rituels de la Cène. Le culte eucharistique réformé à Genève, $\mathrm{XVI}^{\mathrm{e}}-\mathrm{XVII}{ }^{\mathrm{e}}$ siècles
}

Genève, Droz, 2008, 760 p.

Pascale Gruson

\section{(2) OpenEdition}

12 Journals

\section{Édition électronique}

URL : http://journals.openedition.org/assr/21576

DOI : $10.4000 /$ assr.21576

ISSN : $1777-5825$

Éditeur

Éditions de l'EHESS

\section{Édition imprimée}

Date de publication : 31 décembre 2009

ISBN : 978-2-7132-2218-4

ISSN : 0335-5985

\section{Référence électronique}

Pascale Gruson, «Christian GRosse, Les rituels de la Cène. Le culte eucharistique réformé à Genève, $\mathrm{xvI}^{\mathrm{e}}$-xvII ${ }^{\mathrm{e}}$ siècles », Archives de sciences sociales des religions [En ligne], 148 | octobre-décembre 2009, document 148-62, mis en ligne le 15 novembre 2012, consulté le 21 septembre 2020. URL : http:// journals.openedition.org/assr/21576 ; DOI : https://doi.org/10.4000/assr.21576

Ce document a été généré automatiquement le 21 septembre 2020.

(c) Archives de sciences sociales des religions 


\title{
Christian GROSSE, Les rituels de la Cène. Le culte eucharistique réformé à Genève, $\mathrm{XVI}^{\mathrm{e}}-\mathrm{XVII}^{\mathrm{e}}$ siècles
}

Genève, Droz, 2008, 760 p.

\author{
Pascale Gruson
}

\section{RÉFÉRENCE}

Christian GRosSE, Les rituels de la Cène.

Le culte eucharistique réformé à Genève,

$\mathrm{XVI}^{\mathrm{e}}$-XVII ${ }^{\mathrm{e}}$ siècles, Genève, Droz, 2008, $760 \mathrm{p}$.

$148-62$

1 À s'en tenir à l'historiographie traditionnelle du protestantisme, par exemple celle qui se dégage des travaux d'Albert Réville, on pourrait penser que les principaux acteurs de la Réforme (et ceux qui les ont suivis) n'attachaient qu'une importance secondaire aux mises en forme rituelles et liturgiques qui pouvaient l'accompagner. Ayant rompu avec toutes les pratiques potentiellement magiques de l'Église romaine (Grands pardons, cultes des saints, indulgences, etc.), la Réforme privilégiait le développement des vertus de l'intériorité. Pour autant, l'affirmation d'un engagement, d'une foi, peut-elle se passer de tout rituel ? Peut-elle être socialement reconnue sans signe visible, sans un minimum de pratique communautaire ? À partir d'un problème d'apparence très pointue - comment célèbre-t-on la cène dans l'Église réformée de Genève au temps de Calvin ? -, ce sont ces questions et, plus généralement, celles qui traitent de la place des rituels dans toute vie en société, que Christian Grosse veut faire partager à ses lecteurs. Et il a su les rendre, historiquement, sociologiquement, anthropologiquement, significatives.

2 On appréhende, dès les premières pages, la fécondité du cas d'école choisi pour en traiter : dans la première moitié $\mathrm{du} \mathrm{XVI}^{\mathrm{e}}$ siècle, Genève veut préserver l'indépendance 
qu'elle a acquise vis-à-vis du Duché de Savoie; comment fonder concrètement et durablement sa différence ? Quels repères - socialement significatifs - utiliser ?

L'adoption de la Réforme fut, on le sait, le premier geste important. Mais pour quelles raisons et à quelles conditions a-t-il eu l'efficacité que l'on sait?

Certes, dès 1526, la prédication évangélique avait suscité des transgressions socialement très significatives, telles l'obstruction des cultes, la contestation des principaux rituels, le refus de respecter les jeûnes traditionnels ou celui de sonner les cloches dans des circonstances équivoques (la soi-disant résurrection d'enfants mortnés, par exemple), etc. Mais il fallait transformer «l'essai », être capable d'affronter tous les problèmes pratiques résultant de ce choix. Comment préserver un «ordre social»? Comment traiter certaines affaires jusque-là jugées du seul point de vue d'un habitus catholique? C'est là que l'intervention de Calvin et de Farel fut décisive, quoique âprement discutée parfois : d'une part, ils ont très vite comblé le vide créé par l'abandon de la messe et de ses divers rituels; d'autre part, ils ont entrepris de séparer la juridiction civile (les attributions du Grand et du Petit Conseil) et la juridiction religieuse relevant de la stricte discipline ecclésiastique (les attributions du Consistoire, l'instance nouvelle créée à cet effet).

5 La mise en forme d'un culte où la célébration de la Cène garde une place centrale, mais prend un sens complètement renouvelé du fait de la prédication qui y prépare, a été particulièrement efficace. Complétée par une liturgie où le chant des psaumes, la confession de foi et la prière d'intercession tournée vers des responsabilités intramondaines, cette célébration soulignait les exigences envers soi-même et envers autrui qui se déduisent du salut par la grâce. Dès lors, participer à la Cène était un engagement dont la sincérité ne pouvait être appréciée que par le corps pastoral et hors de toute considération mondaine. Reconnaître le salut par la grâce seule, et non par les œuvres, privait la juridiction civile d'en appeler à la religion pour fonder ses jugements, y compris d'excommunication, très utilisée à l'époque. À cette liturgie se sont ajoutés un certain nombre d'aménagements. Il n'y avait plus de fêtes liturgiques à proprement parler, car elles auraient pu être l'occasion d'idolâtrie ; en revanche, tous les dimanches étaient jours chômés pour se rendre au culte. Bien évidemment, ces choix étaient âprement discutés au fur et à mesure que se présentaient des situations concrètes posant problème.

Dans les premiers temps, des points hautement symboliques - la célébration sous les deux espèces, l'usage d'un pain azyme ou d'un pain ordinaire - ont été à l'origine de graves malentendus entre les autorités de Genève et Calvin. Et lorsque le partage des pouvoirs a été mieux admis, restaient nombre de prétextes à remettre en question des équilibres encore fragiles: telle personne non admise à la cène par le Consistoire paraissait très méritante au Petit Conseil, ou inversement. Que faire si, lors d'un voyage, un citoyen de Genève se trouvait en terre catholique : lui serait-il encore possible d'aller à la messe (pour des raisons contingentes) sans subir un reproche d'apostasie ? L'auteur évoque les nombreux cas litigieux qui ont été consignés dans les registres de la ville et du consistoire. Au fil des pages, on comprend donc que Servet et Castellion ne furent pas les seules victimes de la surenchère morale entre Petit conseil et Consistoire. On comprend aussi pourquoi, après la mort de Calvin, la forme liturgique a été assez souvent adaptée à des impératifs circonstanciels plus respectueux des pouvoirs en place. Autrement dit, le sens donné au salut «par la grâce seule » n'a pas manqué de se modifier, tantôt plus libéral, tantôt plus restrictif, ce qui s'est traduit 
par de houleux débats sur le sens de la prédestination, par une organisation des cultes centrée tantôt sur la prédication, tantôt sur la cène, par un choix des fêtes religieuses plus ou moins large, etc.

7 Extrêmement bien documenté et bien écrit, ce livre épais se lit avec aisance et plaisir ; les scènes de la vie de Genève au $\mathrm{XVI}^{\mathrm{e}}$ siècle qui y sont rapportées sont une mine d'information, pour le chercheur, de toute évidence, mais aussi pour le profane.

8 Restent bien sûr des questions portant sur quelques choix interprétatifs de l'auteur. On peut par exemple discuter ce qu'il dit de Max Weber. Ce dernier s'est montré, contrairement à ce qui est affirmé ici, très sensible aux aspects liturgiques de la Réforme, au contenu des Confessions de foi et des catéchismes, aux problèmes pratiques posés par le thème de la prédestination. Et on lui doit, bien sûr, d'avoir mis en évidence ce fait que, pour certains, la quête angoissée d'une confirmation visible de l'élection (au sein de leur communauté) a eu un impact sur leur mode d'action sociale (y compris une forme de développement économique fondée sur l'organisation rationnelle du travail). Christian Grosse ne confondraitil pas les thèses de Weber avec celles de Harnack ou de Troeltsch. On peut discuter aussi le refus appuyé de prendre en considération la dimension théologique de la Réforme : le mode nouveau de célébration de la cène institué par Calvin à Genève, lequel suit encore la trame de la plupart des liturgies réformées contemporaines, s'inscrivait-il seulement dans une contingence pratique ? Il fallait bien que rites et liturgie s'articulent sur la théologie de Luther. Il fallait bien qu'il y eût des relais pastoraux, des académies de formation, des vues d'ensemble. Ce qui avait été ainsi engagé s'inscrivait dans une dynamique sociale que l'on ne perçoit pas toujours clairement.

9 Il n'empêche, ce travail a su mettre à jour ce qui reste une inconnue pour beaucoup, les raisons d'être d'un culte protestant dans une forme qui garde les principaux enseignements de l'Église primitive. Par là-même, il donne à voir de nouvelles conditions de socialisation, ainsi que la mise en forme d'une disposition d'esprit qui a largement contribué à élargir le champ politique du développement social. 